\title{
Predictors of Difficult Intubation in Patients With Ankylosing Spondylitis: Do Disease Activity and Spinal Mobility Indices Matter?
}

\author{
Nilgun ÜSTÜN,,${ }^{1}$ Fatih TOK,,${ }^{2}$ Işıl DAVARCI, ${ }^{3}$ Erman YAĞIZ, ${ }^{1}$ Hayal GÜLER, ${ }^{1}$ \\ Selim TURHANOĞLU, ${ }^{3}$ Ayşe TURHANOĞLU ${ }^{1}$ \\ ${ }^{1}$ Department of Physical Medicine and Rehabilitation, Medical Faculty of Mustafa Kemal University, Hatay, Turkey \\ ${ }^{2}$ Department of Physical Medicine and Rehabilitation, İskenderun Marine Regiment E1 Type Medical Centre, Hatay, Turkey \\ ${ }^{3}$ Department of Anesthesiology and Reanimation, Medical Faculty of Mustafa Kemal University, Hatay, Turkey
}

\begin{abstract}
Objectives: This study aims to determine the predictors of difficult intubation and their possible correlations with disease activity and spinal mobility indices in patients with ankylosing spondylitis.

Patients and methods: Forty-five ankylosing spondylitis patients were included in the study. Disease activity was evaluated with the Bath Ankylosing Spondylitis Disease Activity Index and spinal mobility with Bath Ankylosing Spondylitis Metrology Index (BASMI). The predictors of difficult intubation were evaluated by using the modified Mallampati test, upper lip bite test, thyromental distance, sternomental distance, interincisor distance and neck extension.

Results: There was no correlation between Bath Ankylosing Spondylitis Disease Activity Index and predictive test values (all $p>0.05$ ). There were significant correlations between BASMI with modified Mallampati test, sternomental distance, neck extension, and inter-incisor distance values (all $\mathrm{p}<0.05$ ). The BASMI scores in patients with two or more predictors were significantly higher than BASMI scores in patients with none or one predictor $(5.28 \pm 2.12$ vs. $1.58 \pm 1.50 ; \mathrm{p}<0.001)$. Among the patients with moderate to severe $B A S M l$, the number of patients with two or more predictors was higher than in those patients with none or one predictor $(p=0.001)$

Conclusion: Neck extension, inter-incisor distance, sternomental distance and modified Mallampati test are significant predictors for difficult intubation in patients with ankylosing spondylitis. These predictors were found to be correlated with spinal mobility index, but not with disease activity index. Clinicians should be aware of difficult intubation in ankylosing spondylitis patients with moderate to severe spinal mobility limitation. Key words: Ankylosing spondylitis; difficult intubation; disease activity index; predictor; spinal mobility index.
\end{abstract}

Ankylosing spondylitis (AS) is a chronic inflammatory rheumatic disease characterized by inflammation of the entheses and joints, which may lead to ankylosis. ${ }^{1,2}$ Chronic inflammation leading to progressive ligament/joint ossification in the cervical spine and temporomandibular joints may cause difficult intubation due to reduced cervical spine motion and mouth opening in patients with AS. ${ }^{1,2}$

The reported incidence of a difficult endotracheal intubation varies from $1.5 \%$ to $13 \%$ of patients undergoing surgery. ${ }^{3}$ Failed tracheal intubation with subsequent inability to maintain an open airway and adequate oxygenation is not a common complication, however, it is the most frequent cause of brain damage or death during anesthesia. Safe airway management is crucial in anesthesiology and resuscitation.

Many methods have been introduced to predict difficult airways, of which some require particular circumstances, and some require special equipment. The modified Mallampati test (MMT), neck extension (NE), interincisor distance (IID), thyromental distance (TMD), and the sternomental distance (SMD) are commonly used as predictors of difficult intubation. ${ }^{4,5}$

Although the correlation between disease activity and the commonly used predictors of difficult intubation in rheumatoid arthritis has been

Received: February 03, 2014 Accepted: March 01, 2014

Correspondence: Nilgun Üstün, M.D. Mustafa Kemal Üniversitesi Tıp Fakültesi Fiziksel Tıp ve Rehabilitasyon Anabilim Dalı, 31000 Hatay, Turkey.

Tel: +90 326 - 2291000 e-mail: drnustun@yahoo.com.tr

○2014 Turkish League Against Rheumatism. All rights reserved. 
investigated, there is no data regarding AS in the hitherto literature. Moreover, the aforementioned predictors of difficult intubation are mainly focusing on the temporomandibular joint and cervical spine motion, which have an indispensable relation with disease activity and spinal mobility indices. Accordingly, in this article, we aimed to determine predictors of difficult intubation and their correlations with disease activity and spinal mobility indices in patients with AS for the first time in the literature.

\section{PATIENTS AND METHODS}

We designed a cross-sectional observational study including 45 patients (36 males, 9 females; mean age $42.71 \pm 10.89$ years; range 23 to 70 years) with established AS according to the modified New York criteria. ${ }^{6}$ Ethical approval for this study was provided by the Ethical Committee of Mustafa Kemal University Medical School. The study was carried out by the Departments of Physical Medicine and Rehabilitation and Anesthesiology. Informed consent forms were obtained from the patients.

Disease activity by the Bath Ankylosing Spondylitis Disease Activity Index (BASDAI) ${ }^{7}$ and spinal mobility by the Bath Ankylosing Spondylitis Metrology Index $(\mathrm{BASMI})^{8}$ were measured by the same experienced physical medicine and rehabilitation specialist. The BASDAI includes six patient-reported items of back pain, fatigue, peripheral joint pain and swelling, localized tenderness, and the duration and severity of morning stiffness. It ranges from 0 (no activity) to 10 (maximal activity). A BASDAI score $\geq 4$ represents moderate to high disease activity.

The BASMI is a composite score based on five direct measurements of spinal mobility: lateral lumbar flexion, tragus-to-wall distance, lumbar flexion, intermalleolar distance, and cervical rotation angle. It ranges from 0 (no impairment) to 10 (maximal impairment). BASMI $<3.2$ represent low and scores $\geq 3.2$ represent moderate to severe spinal mobility involvement. ${ }^{8}$

In predicting a difficult intubation, the same experienced anesthesiologist measured the MMT, TMD, SMD, IID, NE and the upper lip bite test (ULBT). NE was measured in patients in the supine position, with the others sitting in the upright position. The IID, TMD and SMD were measured with a ruler and NE with a goniometer.

The MMT was classified as class I (soft palate, fauces, uvula and pillars visible), class II (soft palate, fauces, uvula visible), class III (soft palate and base of uvula visible) and class IV (soft plate not visible). Oropharyngeal examination was performed with the the aid of a flashlight while patients in a sitting position with the tongue fully protruding. The ULBT was classified as class I (lower incisors can bite the upper lip above the vermilion line), class II (lower incisors can bite the upper lip below the vermilion line) and class III (lower incisors cannot bite the upper lip). The SMD was determined as the straight distance between the upper border of the manubrium sterni and the body point of the sternum while the patients in sitting position with the head fully extended and with the mouth closed. The TMD was determined as the straight distance between the upper border of the thyroid cartilage and the bony point of the mentum. Interincisor distance was determined as the distance between incisors while the mouths of the patients in open position. NE was measured in the supine position with the neck fully extended. The angle between the mouth cornertragus line and the horizontal line was measured.

The MMT class III or IV, $, 9,10$ ULBT class III, $, 5,10,11$ TMD $<6.5 \mathrm{~cm}^{4,5,12}$ SMD $<12.5 \mathrm{~cm}$, $4,5,13$ IID $<4 \mathrm{~cm}^{5,14}$ and $\mathrm{NE}<85^{\circ 15,16}$ were considered as predictors of difficult intubation based on previous literatures.

\section{Statistical analysis}

Statistical analysis was performed using the SPSS (SPSS Inc., Chicago, IL, USA) for Windows version 13.0 software. The Kruskal-Wallis, Friedman and Chi-square tests were used for comparison of parameters. Correlation analysis was evaluated by the Spearman correlation analysis. A $p$ value of $<0.05$ was considered statistically significant.

\section{RESULTS}

The mean disease duration was $13.17 \pm 9.49$ years. The mean BASDAI score was $2.58 \pm 1.75$, and the BASMI score was $2.73 \pm 2.42$. Eight patients (18\%) had moderate to high disease activity, while sixteen patients (36\%) had medium to severe BASMI scores. 
Table 1. Descriptive characteristics of predictors, and number of patients with predictors

\begin{tabular}{|c|c|c|c|c|c|}
\hline & \multirow[t]{2}{*}{ Range } & \multirow[t]{2}{*}{ Normal values } & \multirow{2}{*}{$\frac{\text { Patients' values }}{\text { Mean } \pm \text { SD }}$} & \multicolumn{2}{|c|}{ Patients with predictors } \\
\hline & & & & $\mathrm{n}$ & $\%$ \\
\hline Modified Mallampati test & $1-4$ & 1 or 2 & $1.53 \pm 0.81$ & 7 & 16 \\
\hline Sternomental distance & & $12.5 \mathrm{~cm}$ & $19.45 \pm 3.78$ & 6 & 13 \\
\hline Neck extension & & $85^{\circ}$ & $84.33 \pm 13.50$ & 25 & 56 \\
\hline Inter-incisor distance & & $4 \mathrm{~cm}$ & $4.74 \pm 0.71$ & 13 & 29 \\
\hline Upper lip bite test & $1-3$ & 1 or 2 & $1.07 \pm 0.25$ & 0 & 0 \\
\hline Thyromental distance & & $6.5 \mathrm{~cm}$ & $10.30 \pm 1.87$ & 0 & 0 \\
\hline
\end{tabular}

Table 1 shows the descriptive characteristics of the predictors, and the frequencies of the patients with predictors. Fifty-six percent of patients had NE, 29\% of patients had IID, 16\% of patients had MMT, while $13 \%$ of patients had SMD. None of the patients had ULBT or TMD.

There was no correlation between the BASDAI score and any of the predictive test values (all $p>0.05$ ). There were significant correlations between BASMI and MMT, SMD, NE, and IID (all $p<0.05 ; \mathrm{r}=0.660$, $r=-0.479, r=-0.762, r=-0.436$, respectively). There was no correlation between BASMI with ULBT and TMD (both $\mathrm{p}>0.05$ ).

The BASMI and BASDAI scores of the patients according to the predictors are shown on Table 2. The BASMI scores of patients with two or more predictors were significantly higher than BASMI scores of patients with none or one predictor (5.28 \pm 2.12 vs. $1.58 \pm 1.50 ; p<0.001)$.

Among the patients with moderate to severe BASMI, the number of patients with two or more predictors was higher than that of patients with none or one predictor ( $26.6 \%$ vs. $8.8 \%, p=0.001$ ) (Figure 1).

\section{DISCUSSION}

This study describes predictors of difficult intubation and their correlation with disease activity/mobility indices in patients with AS. The findings revealed that NE, IID, SMD and MMT were significant predictors of difficult intubation in the patients. Additionally, these predictors were found to be correlated with the spinal mobility index and not with the disease activity index. On the other hand, the number of patients with two or more predictors was higher than that of patients with none or one predictor in patients with moderate to severe spinal mobility impairment.

Patients with AS may present tremendous challenges to the anesthesiologists due to fusion of the cervical and thoracal spine, and stiffness of the temporomandibular joint. ${ }^{16}$ Reduced cervical and thoracolumbar spine mobility, and temporomandibular joint disease are common in the patients with long lasting AS. ${ }^{17-19}$ About $50 \%$ of patients with AS have cervical spine radiological involvement after 15 years, and $70 \%$ after 20 years. ${ }^{20}$ Temporomandibular joint involvement occurs in $10 \%$ of patients, whereas it

Table 2. Spinal Mobility Index, Bath Ankylosing Spondylitis Index and Bath Ankylosing Spondylitis Disease Activity Index scores in patients with one or more predictors

\begin{tabular}{|c|c|c|c|c|}
\hline & \multicolumn{2}{|c|}{ Patients with predictors } & \multirow{2}{*}{$\frac{\text { BASMI score }}{\text { Mean } \pm \text { SD }}$} & \multirow{2}{*}{$\frac{\text { BASDAI score }}{\text { Mean } \pm \text { SD }}$} \\
\hline & $\mathrm{n}$ & $\%$ & & \\
\hline Reduced NE & 25 & 55.5 & $3.8 \pm 2.59$ & $2.54 \pm 1.86$ \\
\hline Reduced IID & 13 & 28.8 & $4.46 \pm 1.98$ & $2.64 \pm 1.71$ \\
\hline Increased MMT & 7 & 15.5 & $6.57 \pm 2.29$ & $2.91 \pm 2.27$ \\
\hline Reduced SMD & 6 & 13.3 & $5.16 \pm 2.63$ & $2.5 \pm 1.66$ \\
\hline Reduced NE and IID & 10 & 22.2 & $5.10 \pm 1.79$ & $2.51 \pm 1.89$ \\
\hline Reduced NE and IID and increased MMT & 4 & 8.8 & $6.5 \pm 2.08$ & $2.5 \pm 1.85$ \\
\hline Reduced NE, IID and SMD & 4 & 8.8 & $6.50 \pm 2.08$ & $2.3 \pm 2.06$ \\
\hline Reduced NE, IID and SMD and increased MMT & 3 & 6.6 & $7.33 \pm 1.52$ & $2.93 \pm 2.00$ \\
\hline
\end{tabular}


may increase up to $30-40 \%$ when the disease is long standing. ${ }^{21}$ Patients in this study had 13 years of disease duration (long-lasting disease). About half of the patients had reduced NE, while one-third of the patients had reduced temporomandibular joint motion. These findings are comparable with those mentioned in publications which assessed radiological involvement.

There was no correlation between disease activity and predictors of difficult intubation. This may be due to the nature of BASDAI, the most frequently used measure of disease activity in clinical trials, which demonstrates the current inflammatory status of the disease alone, and not long-term structural damage as in spinal mobility index. ${ }^{7}$ Çağla Özbakış Akkurt et al. ${ }^{22}$ reported no correlation between disease activity and any predictors of difficult intubation in patients with rheumatoid arthritis.

Measurement of spinal mobility based on lateral lumbar flexion, tragus-to-wall distance, lumbar flexion, intermalleolar distance and cervical rotation angle is a key clinical assessment of AS to monitor disease progression. ${ }^{23}$ MMT, SMD, NE and IID are commonly used predictors in clinical practice. MMT classifies visibility of the oropharyngeal structure., ${ }^{9,24}$ MMT assesses not only oropharyngeal structure, but also head and neck mobility and mouth opening. SMD

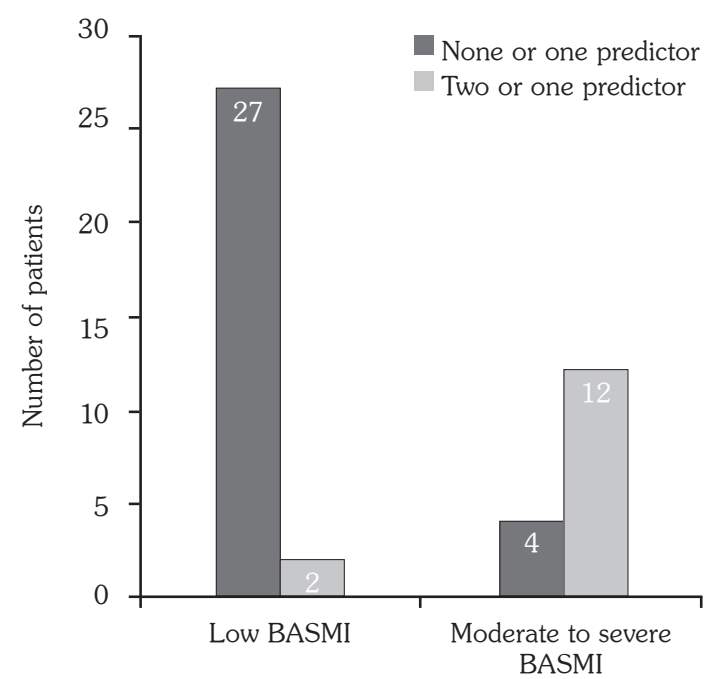

Figure 1. Number of patients according to bath ankylosing spondylitis metrology index subgroups and number of the predictors. BASMI: Bath Ankylosing Spondylitis Metrology Index. can be used as an indicator of head and neck mobility. IID measures the movement of the temporomandibular joint. In this study, there were unsurprisingly strong significant correlations between BASMI with NE, IID, MMT and SMD. BASMI may be used as an indicator for difficult intubation in clinical practice unlike BASDAI.

Furthermore, a test to predict difficult intubation should have high sensitivity to identify most patients in whom intubation will truly be difficult. ${ }^{25}$ Currently available screening tests for difficult intubation have only poor to moderate sensitivity when used alone. However, combinations of individual tests add some incremental diagnostic value in comparison to the value of each test alone., ${ }^{5,6}$ In this study, among patients with moderate to severe BASMI, the number of patients with two or more predictors was significantly higher than that of patients with none or one predictor. Clinicians should be careful when evaluating difficult intubation in patients with moderate to severe BASMI.

The other likely problem in patients with AS during intubation is that AS patients are susceptible to vertebral fractures even from minor trauma, because of the rigid/deformed vertebra and accompanying osteoporosis. ${ }^{26}$ AS patients with hip joint involvement can present tremendous challenges to the gynecologists with the patients in the lithotomy position due to fusion of the hip joints. ${ }^{27}$

On the other hand, the present study has some limitations; primarily the small patient group with male predominance, and the lack of patients undergoing surgery; thus the relation between clinical indices and actual difficult intubation were not be able to be considered. Nevertheless, the results appear to be significant.

In conclusion; NE, IID, SMD and MMT are significant predictors of difficult intubation in patients with AS. These predictors were found to be correlated with involvement of spinal mobility, but not with disease activity. This clinical data may draw the attention of clinicians about unanticipated difficult intubation in patients with AS patients who have moderate to severe impairment of spinal mobility. Future larger studies, which included the patients undergoing surgery, are needed to clarify the significance of this finding. 


\section{Declaration of conflicting interests}

The authors declared no conflicts of interest with respect to the authorship and/or publication of this article.

\section{Funding}

The authors received no financial support for the research and/or authorship of this article.

\section{REFERENCES}

1. Zochling J, Braun J. Assessments in ankylosing spondylitis. Best Pract Res Clin Rheumatol 2007;21:699-712.

2. Mansour M, Cheema GS, Naguwa SM, Greenspan A, Borchers AT, Keen CL, et al. Ankylosing spondylitis: a contemporary perspective on diagnosis and treatment. Semin Arthritis Rheum 2007;36:210-23.

3. Randell T. Prediction of difficult intubation. Acta Anaesthesiol Scand 1996;40:1016-23.

4. Shiga T, Wajima Z, Inoue T, Sakamoto A. Predicting difficult intubation in apparently normal patients: a meta-analysis of bedside screening test performance. Anesthesiology 2005;103:429-37.

5. Khan ZH, Mohammadi M, Rasouli MR, Farrokhnia F, Khan $\mathrm{RH}$. The diagnostic value of the upper lip bite test combined with sternomental distance, thyromental distance, and interincisor distance for prediction of easy laryngoscopy and intubation: a prospective study. Anesth Analg 2009;109:822-4.

6. van der Linden S, Valkenburg HA, Cats A. Evaluation of diagnostic criteria for ankylosing spondylitis. A proposal for modification of the New York criteria. Arthritis Rheum 1984;27:361-8.

7. Garrett S, Jenkinson T, Kennedy LG, Whitelock H, Gaisford P, Calin A. A new approach to defining disease status in ankylosing spondylitis: the Bath Ankylosing Spondylitis Disease Activity Index. J Rheumatol 1994;21:2286-91.

8. Jenkinson TR, Mallorie PA, Whitelock HC, Kennedy LG, Garrett SL, Calin A. Defining spinal mobility in ankylosing spondylitis (AS). The Bath AS Metrology Index. J Rheumatol 1994;21:1694-8.

9. Samsoon GL, Young JR. Difficult tracheal intubation: a retrospective study. Anaesthesia 1987;42:487-90.

10. Khan ZH, Kashfi A, Ebrahimkhani E. A comparison of the upper lip bite test (a simple new technique) with modified Mallampati classification in predicting difficulty in endotracheal intubation: a prospective blinded study. Anesth Analg 2003;96:595-9.

11. Salimi A, Farzanegan B, Rastegarpour A, Kolahi AA. Comparison of the upper lip bite test with measurement of thyromental distance for prediction of difficult intubations. Acta Anaesthesiol Taiwan 2008;46:61-5.

12. Amathieu R, Combes X, Abdi W, Housseini LE, Rezzoug A, Dinca A, et al. An algorithm for difficult airway management, modified for modern optical devices (Airtraq laryngoscope; LMA CTrach ${ }^{\mathrm{TM}}$ ): a 2-year prospective validation in patients for elective abdominal, gynecologic, and thyroid surgery. Anesthesiology 2011;114:25-33.

13. Pinar E, Calli C, Oncel S, Selek B, Tatar B. Preoperative clinical prediction of difficult laryngeal exposure in suspension laryngoscopy. Eur Arch Otorhinolaryngol 2009;266:699-703.

14. Fritscherova S, Adamus M, Dostalova K, Koutna J, Hrabalek L, Zapletalova J, et al. Can difficult intubation be easily and rapidly predicted? Biomed Pap Med Fac Univ Palacky Olomouc Czech Repub 2011;155:165-71.

15. Soyuncu S, Eken C, Cete Y, Bektas F, Akcimen M. Determination of difficult intubation in the $\mathrm{ED}$. Am J Emerg Med 2009;27:905-10.

16. Wilson ME, Spiegelhalter D, Robertson JA, Lesser P. Predicting difficult intubation. Br J Anaesth 1988;61:211-6.

17. Bourlier RA, Birnbach DJ. Anesthetic management of the parturient with ankylosing spondylitis. Int $\mathrm{J}$ Obstet Anesth 1995;4:244-7.

18. Ibn Yacoub Y, Amine B, Laatiris A, Bensabbah R, Hajjaj-Hassouni N. Relationship between diagnosis delay and disease features in Moroccan patients with ankylosing spondylitis. Rheumatol Int 2012;32:357-60.

19. Brophy S, Mackay K, Al-Saidi A, Taylor G, Calin A. The natural history of ankylosing spondylitis as defined by radiological progression. J Rheumatol 2002;29:1236-43.

20. Jang JH, Ward MM, Rucker AN, Reveille JD, Davis $\mathrm{JC} \mathrm{Jr}$, Weisman $\mathrm{MH}$, et al. Ankylosing spondylitis: patterns of radiographic involvement--a re-examination of accepted principles in a cohort of 769 patients. Radiology 2011;258:192-8.

21. El Maghraoui A, Bensabbah R, Bahiri R, Bezza A, Guedira N, Hajjaj-Hassouni N. Cervical spine involvement in ankylosing spondylitis. Clin Rheumatol 2003;22:94-8

22. Cagla Ozbakis Akkurt B, Guler H, Inanoglu K, Dicle Turhanoglu A, Turhanoglu S, Asfuroglu Z. Disease activity in rheumatoid arthritis as a predictor of difficult intubation? Eur J Anaesthesiol 2008;25:800-4.

23. van der Heijde D, Calin A, Dougados M, Khan MA, van der Linden S, Bellamy N. Selection of instruments in the core set for DC-ART, SMARD, physical therapy, and clinical record keeping in ankylosing spondylitis. Progress report of the ASAS Working Group. Assessments in Ankylosing Spondylitis. J Rheumatol 1999;26:951-4.

24. Mallampati SR, Gatt SP, Gugino LD, Desai SP, Waraksa B, Freiberger D, et al. A clinical sign to predict difficult tracheal intubation: a prospective study. Can Anaesth Soc J 1985;32:429-34.

25. Arné J, Descoins P, Fusciardi J, Ingrand P, Ferrier B, Boudigues D, et al. Preoperative assessment for difficult intubation in general and ENT surgery: predictive value of a clinical multivariate risk index. $\mathrm{Br} \mathrm{J}$ Anaesth 1998;80:140-6.

26. Gündüz OH, Yagci L, Kiralp MZ, Ozçakar L. Sudden increase of neck flexion in ankylosing spondylitis: quo vadis? Acta Reumatol Port 2009;34:141-2.

27. Ozçakar L, Yarali H. Ankylosing spondylitis: an impending restraint for gynecological interventions? Rheumatol Int 2004;24:123. 